\title{
UM ESTUDO SOBRE OS “VERDADEIROS” E OS “FALSOS” DITONGOS EM PORTUGUÊS
}

Nívea Rohling da Silva Mestre em Linguística e Doutoranda em Linguística pela UFSC.

\section{RESUMO}

Neste artigo, objetiva-se apresentar uma análise do ditongo em português a partir da distinção entre os ditongos decrescentes e os ditongos crescentes na sua correlação com os ditongos verdadeiros e os falsos ditongos. A pesquisa está embasada na teoria estruturalista e na fonologia multilinear, tendo como foco os estudos de Bisol (1989) para a análise do ditongo. Este estudo mostrou que a diferença entre os ditongos (decrescente e crescente) está ligada à posição da glide na estrutura silábica.

Palavras-chave: Ditongo em português. Verdadeiro ditongo. Falso ditongo.

\section{ABSTRACT}

The aim of this article is to present an analysis of the diphthong in Portuguese through the distinction between opening and closing diphthongs and their relation with proper and improper diphthongs. The research is based on the structuralism theory and Multilinear Phonology, it also focuses on Bisol (1988) studies for the diphthong analyses. This study showed that the difference between opening and closing diphthongs is linked to the glide position in the syllabic structure.

Keywords: Diphthong in Portuguese. Improper Diphthong. Proper Diphthong.

\section{Introdução}

Este artigo apresenta um estudo introdutório sobre a formação dos ditongos em português. Para tanto, inicialmente são apresentados alguns pressupostos básicos sobre a constituição da sílaba e sistema vocálico do português. Na sequência, é realizada uma caracterização do ditongo em português, para então discutir questões como a noção de verdadeiros e falsos ditongos na perspectiva de Bisol (1989).

\section{Pressupostos teóricos}

Para uma análise do ditongo em português a partir da distinção entre os ditongos decrescentes e os ditongos crescentes é necessário verificar alguns preceitos teóricos prévios como, por exemplo, a constituição da sílaba e do sistema vocálico do português, tendo em vista que a constituição do ditongo está intrinsecamente ligada a estes dois sistemas. Nesta seção, será abordada a conceituação de sílaba em português proposto no estudo de Mattoso Câmara Jr. 
(1969) e Collischonn (2001); também será apresentado o sistema vocálico do português de Câmara Jr. (1969).

Com relação à constituição da sílaba, Mattoso Câmara Jr. (1969, p.26) propõe que: "os fonemas (vogais e consoantes) funcionam na enunciação lingüística combinados numa unidade superior, (...) conhecida tradicionalmente por sílaba". Ou seja, na perspectiva mattosiana compreende-se por sílaba a combinação das vogais e consoantes. Para o autor, a natureza físicoarticulatória da sílaba é muito complexa e pode ser estruturada sob vários aspectos, conforme se focalize a série de movimentos bucais, ou o impulso expiratório, ou a tensão dos órgãos fonadores, ou o efeito auditivo que resulta de tudo isso (Mattoso Câmara Jr. 1969).

A sílaba é marcada por uma fase ascensional, ou "crescente", um momento de plenitude e uma fase de descensão, ou "decrescente". Assim, quando a sílaba é completa, compõe-se de um aclive, um ápice e um declive (Cf. figura 1).

Figura 1 - Estrutura silábica na proposta de MATTOSO CÂMARA Jr. (1969).

Para Bisol (2001), o ápice é constituído por vogal (momento essencial da sílaba e o fonema que o realiza vem a ser o "silábico"), o aclive por uma ou duas consoantes e o declive por uma das seguintes consoantes $/ S /, / r /$, $/ /$, ou pela semivogal $/ \mathrm{j}, \mathrm{w} /$. Há também a possibilidade de uma consoante nasal compor o declive. Vale destacar que contrariamente à proposta de Bisol (2001) a posição da semivogal no declive não é sustentada por Câmara Jr. (1982).

Outro conceito importante dentro da perspectiva da sílaba na visão mattosiana é o molde silábico que tem como função determinar o número máximo e mínimo de elementos permitidos numa sílaba. Segundo Collinschon (2001), pode-se deduzir o molde silábico do português subjacente à análise mattosiana (Cf. figura 2).

\begin{tabular}{|l|l|}
\hline $\mathrm{V}$ & $\underline{\mathrm{a}}$ \\
\hline $\mathrm{VC}$ & $\underline{\text { ir }}$ \\
\hline $\mathrm{VCC}$ & $\underline{\text { instituto }}$ \\
\hline CV & $\underline{\text { lá }}$ \\
\hline CVC & $\underline{\text { mar }}$ \\
\hline CVCC & $\underline{\text { perspicaz }}$ \\
\hline
\end{tabular}




\begin{tabular}{|l|l|}
\hline CCV & trimestre \\
\hline CCVC & $\underline{\text { crês }}$ \\
\hline CCVCC & $\underline{\text { transportar }}$ \\
\hline VV & $\underline{\text { ouvir }}$ \\
\hline CVV & $\underline{\text { rei }}$ \\
\hline CCVV & pleito \\
\hline CCVVC & claustrofobia \\
\hline
\end{tabular}

Figura 2 - Estrutura silábica do português (adaptado de COLLISCHONN 2001, p.107).

Sobre a constituição da sílaba, Collischonn (2001) afirma que a noção de sílaba em fonologia não é recente, tendo sido incorporada à fonologia gerativa a partir dos trabalhos de Hooper (1976) e Kahn (1976). Entre modelos mais atuais há basicamente duas teorias a respeito da estrutura interna da sílaba:

- Teoria autosegmental (modelo de estrutura plana) - Kahn (1976); Clements e Keyser (1983) prevêem que o relacionamento entre os três elementos é igual.

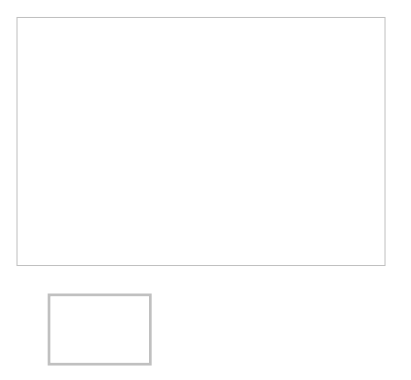

Figura 3 - Estrutura silábica na teoria autosegmental.

- $\quad$ Teoria métrica - (modelos binários) - Pike and Pike (1947) e Fudge (1969) propõem um relacionamento muito mais estreito entre a vogal do núcleo e a consoante da coda do que esta vogal e a consoante do ataque.

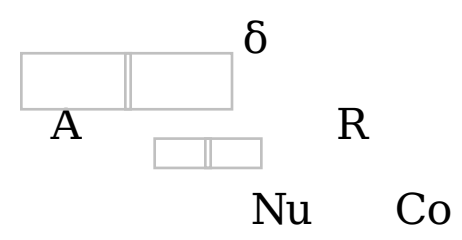

Figura 4 - Estrutura silábica na teoria métrica.

De acordo com Collischonnn (2001, p. 92), “(..) uma sílaba consiste em um ataque (A) e em uma rima (R); a rima por sua vez, consiste em um núcleo (Nu) e coda (Co)". A letra grega $\delta$ simboliza a sílaba e se ramifica em ataque (onset) e rima. O ataque pode ser formado por uma ou duas consoantes e a rima, por vogais, que serão classificados como núcleos, e por consoantes, denominados de coda. Qualquer categoria pode ser vazia, exceto $\mathrm{Nu}$. Segue um exemplo com a palavra 'flores'. 
Com relação ao sistema vocálico do português, a proposta de Câmara Jr. (1953, apud ALTMAN, 2004) baseia-se no acento e identifica 7 sons silábicos: [a] [ $\varepsilon$ ] [e] [i] [ò] [o] [u], e 2 não-silábicos [y] e [w] (Cf. vou [vow], vôo [vou]; sois [soys], soes [sois]) em posição tônica, levando em consideração o seu ponto de articulação, o grau de abertura bucal e o arredondamento dos lábios.

As vogais podem formar uma sílaba isoladamente e serem núcleo de sílaba, ora no início, meio ou fim da palavra independentemente se forem tônicas, pretônicas ou postônicas. Por exemplo: início de palavra: /a/meixa; meio de palavra: po/e/ta; final de palavra: di/a/. Bisol (2001) apresenta o sistema vocálico do português na perspectiva mattosiana da seguinte maneira:

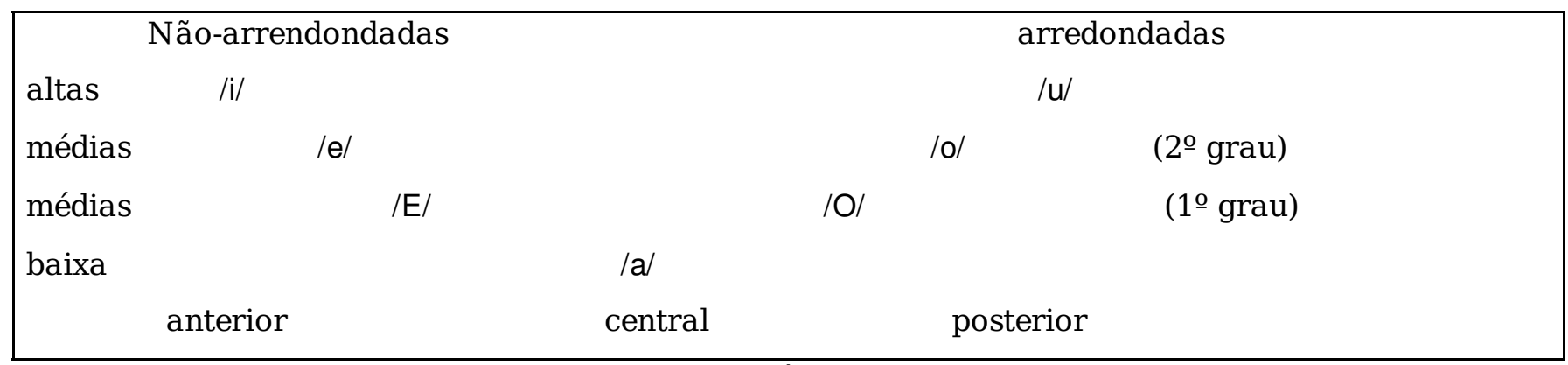

Figura 5 - Vogais em posição tônica (BISOL, 2001, p. 160).

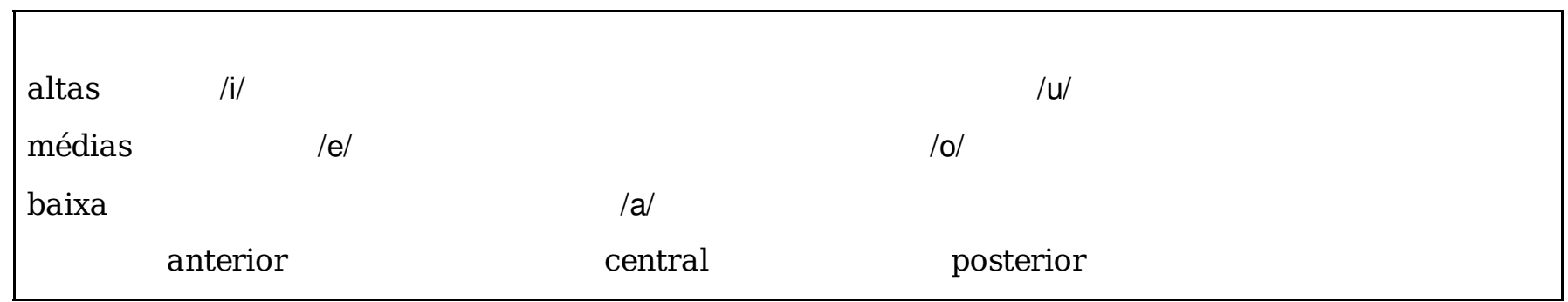

Figura 6 - Vogais em posição tônica diante de nasal (BISOL, 2001, p. 160).

\begin{tabular}{|lccc|}
\hline $\begin{array}{lll}\text { altas } \\
\text { médias }\end{array}$ & $\mathrm{i}$ & & $\mathrm{u}$ \\
baixa & & $\mathrm{e}$ & $\mathrm{o}$ \\
& & $\mathrm{a}$ & \\
& anterior & central & posterior \\
\hline
\end{tabular}

Figura 7 - Vogais em posição pretônica (BISOL, 2001, p. 161). 


\begin{tabular}{|lccc|}
$\begin{array}{l}\text { médias } \\
\text { baixa }\end{array}$ & e & - \\
& & a & \\
& anterior & central & posterior \\
\hline
\end{tabular}

Figura 8 - Vogais em posição postônica não-final (BISOL, 2001, p. 162).

\begin{tabular}{|cccc|}
\hline altas & $\mathrm{i}$ & $\mathrm{u}$ \\
baixa & & $\mathrm{a}$ & \\
& anterior & central & posterior \\
\hline
\end{tabular}

Figura 9 - Vogais em posição postônica final (BISOL, 2001, p. 162).

Nesta seção, foram apresentados, de maneira sucinta, conceitos de sílaba e sistema vocálico em português. Esta conceituação inicial procura dar subsídio à leitura da formação do ditongo em português, considerando-o dentro da estrutura silábica e como parte do sistema vocálico do português. A seguir, será apresentada a constituição dos ditongos em português.

\section{O ditongo em português}

De acordo com Cagliari e Massini (2003), do ponto de vista fonético, os ditongos são vogais que mudam de qualidade durante sua produção. Na articulação dos ditongos o som inicia dentro da área vocálica e se dirige a outro, nesse movimento a vogal sofre alteração acústica. Com relação à formação de ditongos em português Cagliari e Massini (2003, p. 130) afirmam:

[...] em português, há a possibilidade da formação de ditongos e tritongos, cujas margens são ocupadas por vogais outras que não [i] e [u], no nível fonético, mas que costuma ser interpretadas pelo falante/ouvinte como se fossem essas vogais, no nível fonológico [...].

Dessa maneira, tem-se a acepção do ditongo como vogal que assume novas qualidades vocálicas, ou seja, sofre mutação na qualidade articulatória dependendo do movimento da língua durante sua realização (CAGLIARI, 1997). Tal conceito de ditongo é perceptível no exemplo da palavra pai - podendo realizar-se como pai - pae - paE. Portanto, a vogal [i] final assume novo estatuto.

Para compreender a diferença entre uma vogal que não muda seu estatuto e uma que sofre mudanças constituindo um ditongo estabelece-se o seguinte par mínimo: pais e país. Obviamente, esta distinção também passa por questões de prosódia ${ }^{\lfloor 11}$ o próprio acento gráfico evidencia a diferença entre as palavras. Entretanto, é importante observar que o ditongo [ai] apresenta somente uma V, já na palavra país tem-se a seqüência VV, ou seja, são duas realizações vocálicas, 
constituindo sílabas diferentes.

Para constituição do ditongo em português Câmara Jr. (1977) propõe que as vogais $(\mathrm{i} /, / \mathrm{u} /)$ por constituírem as vogais mais fechadas no sistema vocálico do português, assumem, pois, a função assilábica como vogal auxiliar de ditongo. $\mathrm{O}$ autor estabelece como relevante os ditongos que formam contraste distintivo com vogais simples como, por exemplo, as palavras: pá-pai-pau, lê-lei-leu, dó-dói.

Nessa mesma perspectiva, Callou e Leite (1990) afirmam que ocorre ditongo em português quando as vogais $(/ i /, / u /)$ ocupam a posição de margem de sílaba e contrastam com vogais simples. Ainda sobre a constituição dos ditongos, Câmara Jr. (1977, p. 57) propõ $\mathrm{e}^{[2]}$ :

As vogais assilábicas, [...] formam com a silábica um centro de sílaba polifonemático em regra como ditongo decrescente, pois os ditongos crescentes se desfazem em hiatos sem qualquer valor distintivo (fiel, miolo, suar etc), salvo se tem um /w/ com /q/ ou /g/ pré-vocálico (quais / qways/).

Por fim, verifica-se em Faraco (2003) um conceito de ditongo mais próximo da gramática normativa, geralmente, utilizada no ensino de língua portuguesa.

Podemos conceituar ditongo como o encontro de duas vogais ditas numa sílaba (num único impulso de voz). Uma dessas vogais será |i| ou $|u|$, pronunciadas com maior fechamento da passagem do ar, o que as transforma em semivogais, passando a ser representadas pelos símbolos $|\mathrm{y}| \mathrm{e}|\mathrm{w}|$ do alfabeto Fonético Internacional (FARACO, 2003, p. 38).

O autor apresenta também a tradicional classificação do ditongo: oral e nasal; e decrescentes e crescentes, de acordo com a posição da vogal básica (antes ou depois da semivogal).

\section{O ditongo decrescente e ditongo crescente}

Os ditongos decrescentes ocorrem quando a vogal básica precede a semivogal. Para Mattoso Câmara Jr. (1969), os verdadeiros ditongos em português são os decrescentes; pois os crescentes variam livremente com o hiato. De acordo com Callou e Leite (1990), são considerados ditongos decrescentes em português:

\begin{tabular}{|l|l|}
\hline Orais & Nasais \\
\hline aw > pau & a w $\sim>$ mão \\
\hline Ew> réu & a y y mãe \\
\hline iw> riu & o y y põe \\
\hline ow> vou & $\mathrm{u} \sim \mathrm{y} \sim>$ muito, (ruim) \\
\hline ay> pai & e $\sim$ y > tem, ontem \\
\hline Ey> réis & \\
\hline ey> rei & \\
\hline
\end{tabular}




\begin{tabular}{|l|l|}
\hline oy> foi & \\
\hline Oy> rói & \\
\hline uy> fui & \\
\hline
\end{tabular}

Figura 10 - Ditongos decrescentes em português (Adaptado de CALLOU e LEITE, 1990, p. 91).

Na perspectiva de Bisol (1989), na ocorrência dos ditongos decrescentes, a semivogal ocuparia a posição de consoante, localizando-se na coda da sílaba. Nesta acepção, seria possível a comutação das semivogais com consoante na coda como, por exemplo, mar e mau. Já para Câmara Jr. (1982), a semivogal é de natureza vocálica e ocupa junto com a vogal silábica o núcleo da silaba, ou seja, sendo desta maneira inviável a comutação de glide e consoante em posição de coda, considerando possível, somente, a comutação entre glide e a vogal simples como, por exemplo, leu/lê.

Como já foi dito anteriormente, para Câmara Jr. (1969), os verdadeiros ditongos em português são os decrescentes; pois os crescentes variam livremente com o hiato como, por exemplo, sua.ar/suar, su.a.dor/sua.dor. Bisol (1989) também concorda com esta acepção, expondo de maneira mais enfática a não existência do ditongo crescente. A autora defende a posição de que a sequência glidevogal é o resultado de ressilabificação, não assume função alguma no sistema fonológico.

Conforme Bisol (1989, p. 215), “ditongos crescentes são rimas de duas diferentes sílabas na estrutura subjacente". Tal entendimento sobre o ditongo crescente apóia-se no fato de a sequência VV (glide-vogal) estar, geralmente, em variação livre com a vogal alta correspondente. No entanto, segundo Collischonn (2001), há um tipo de ditongo crescente que não alterna com hiato à kw/gw - seguidos de a/o. Ex. qual à [æækaw] *[kuæaw]. E percebe-se uma tendência na língua em libertar-se da sequência consoante velar/glide. Ex. quotidiano à cotidiano. Tais palavras já estão sendo dicionarizadas (cotidiano, catorze). Para tal questionamento, Bisol (1989) apresenta uma contra-argumentação:

A seqüência consoante velar glide posterior mostra um comportamento similar com [t̃] que está em distribuição complementar com [t], ocorrendo somente antes de i. Mas o comportamento não é o mesmo, ditongo versus vogal simples forma pares mínimos. Por exemplo: cal [kal], qual [kwal]. (BISOL, 1989, p.216).

A autora lembra, ainda, que a sequência consoante velar glide posterior é reminiscência do latim - [kw] e [gw] e que são poucas palavras que preservam o grupo latino, então, para Bisol (1989), o glide neste caso situa-se no "onset" não ramificado. 
A autora conclui, reafirmando que o ditongo crescente, exceto aqueles que ocorrem com o grupo latino [kw] e [gw] são estrutura derivadas, ou seja, vogais simples na forma básica, rimas de diferentes sílabas. Para Bisol (1989, p. 217), "No processo de ressilabificação, a vogal alta desligada associa-se à posição precedente ou seguinte". Tal posição se opõe a de Mattoso Câmara Jr. (1982) para quem a glide é de natureza vocálica, e, portanto, ocupa junto com a vogal o núcleo da sílaba.

k

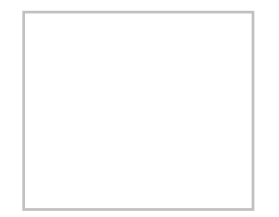

5

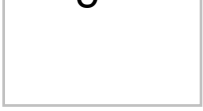

Dessa maneira, o conceito de ditongo crescente em Bisol (1989) desaparece, considerando a glide como formadora de rima de sílaba diferente. É importante ressaltar que a noção de ditongo de ambos os autores está ligada à posição que o glide ocupa na estrutura silábica, por isso, no início deste trabalho expomos uma breve caracterização da sílaba.

\section{O verdadeiro ditongo e o falso ditongo em português}

A partir da apresentação dos ditongos em português o ponto alto deste trabalho está localizado na proposta de ditongo verdadeiro e de falso ditongo. De acordo com Bisol (1989, p. 89), "no português há duas classes de ditongo: ditongo pesado e ditongo leve". A autora apresenta os ditongos pesados como verdadeiros ditongos e os ditongos leves como falsos ditongos.

- Ditongo pesado - está associado a duas posições no "tier" da rima, constitui uma sílaba complexa e tende a ser preservada, por isso é considerado o verdadeiro ditongo. Ex: p[aw]ta à *p[a]ta.

- Ditongo leve - está associado a uma só posição no "tier" da rima, constitui uma rima simples e tende a ser perdido. Ex. p[ej]xe à p[e]xe.
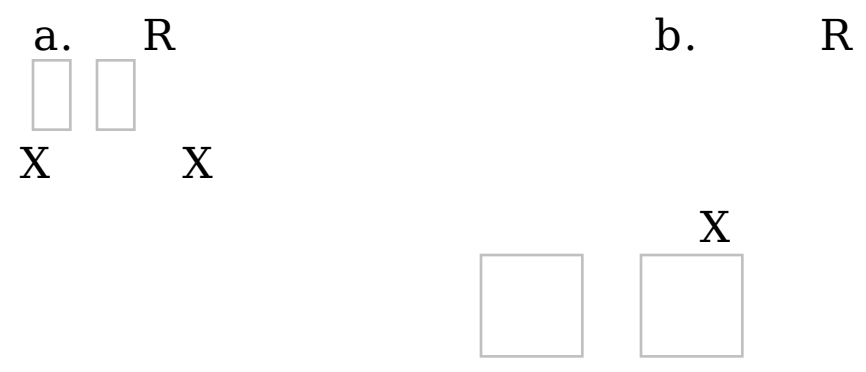
Figura 11- Representações das estruturas subjacentes dos ditongos verdadeiros e falsos (BISOL 1989, p. 190).

Bisol (1989) apresenta outro argumento para acepção de ditongo pesado e leve. O ditongo pesado (verdadeiro) é um ditongo fonológico, pois é possível a formação de pares mínimos com a vogal simples, ou seja, estabelece distinção, constituindo um verdadeiro ditongo. O ditongo leve, por sua vez, não causa distinção, tendo em vista que não é possível formar pares mínimos, constituindo um ditongo fonético, e, portanto, um falso ditongo.

\begin{tabular}{|l|ll|}
\hline $\begin{array}{l}\text { Ditongo pesado (ditongo } \\
\text { fonológico) }\end{array}$ & $\begin{array}{l}\text { Ditongo leve (ditongo } \\
\text { fonético) }\end{array}$ \\
\hline $\mathrm{p}[\mathrm{aw}] \mathrm{ta} \quad \mathrm{pata}$ & $\mathrm{c}[\mathrm{aj}] \mathrm{xa}$ & $\mathrm{c}[\mathrm{a}] \mathrm{xa}$ \\
$\mathrm{r}[\mathrm{ej}] \mathrm{tor}$ & $\mathrm{am}[\mathrm{ej}] \mathrm{xa}$ & $\mathrm{am}[\mathrm{e}] \mathrm{xa}$ \\
$\mathrm{c}[\mathrm{aw}] \mathrm{e} \quad \mathrm{c}[\mathrm{a}] \mathrm{le}$ & $\mathrm{b}[\mathrm{ej]} \mathrm{ra} \quad \mathrm{b}[\mathrm{e}] \mathrm{ra}$ \\
\hline
\end{tabular}

Figura 12 - Exemplos de ditongos fonológicos (possibilidade de pares mínimos) e ditongos fonéticos (não possibilita pares mínimos).

\section{Considerações finais}

O objetivo deste trabalho foi realizar um estudo sobre o ditongo em português. O estruturalismo clássico mattosiano foi a base teórica deste estudo, contudo as novas teorias fonológicas que, de certa maneira, corroboram com as teorias estruturalistas, também contemplaram o presente estudo. A discussão central do texto pautou-se na existência do verdadeiro ditongo (decrescente) e o falso ditongo (crescente) proposta por Bisol (1989). A constituição do ditongo em português é um tema bastante complexo nos estudos fonológicos, podendo ser desdobrado em novas pesquisas.

\section{Referências bibliográficas}

ALTMAN, Cristina . A conexão americana: Mattoso Câmara e o círculo lingüístico de Nova Iorque. DELTA, 2004, vol.20, p.129-158.

BISOL, Leda. O ditongo na perspectiva da fonologia atual. D.E.L.T.A, 1989, vol. 5, n.2: $185-224$.

. Ditongos derivados. D.E.L.T.A., 1994, vol. 10, n. especial, p. 123 -140.

. In: BISOL, Leda (org). Introdução à teoria fonológica. Introdução a estudos de fonologia do português brasileiro. Porto Alegre: EDIPUC-RS, 2001, p. 11 - 89.

CAGLIARI, L. C. Marcadores prosódicos na escrita. Estudos Lingüísticos: anais de seminários do GEL. Lorena, GEL, pp. 195-203, 1989 a. 

. Alfabetização \& lingüística. São Paulo: Editora Scipione,1997.

CAGLIARI, Luiz Carlos; MASSINI-CAGLIARI, Gladis. In: MUSSALIM, Fernanda \& BENTES, Anna Christina (orgs). Fonética. Introdução à lingüística: domínios e fronteiras, v. 1. São Paulo: Cortez Editora, 2003, p. 105-146.

CALLOU, Dinah; LEITE, Yonne. Iniciação à Fonética e à Fonologia . Rio de Janeiro: Jorge Zahar Editor, 1990.

COLLISCHONN, Gisela. A sílaba em português. In: BISOL, Leda (org.). Introdução a estudos de fonologia do português brasileiro. Porto Alegre: EDIPUC-RS, 2001, p. $91-123$.

FARACO, Carlos Alberto. Escrita e alfabetização. São Paulo: Contexto, 2003.

MATTOSO CÂMARA Jr., Joaquim. Problemas de Lingüística Descritiva. Petrópolis: Vozes, 1969. $\overline{1977 .}$ . Para o estudo da fonêmica portuguesa. Rio de Janeiro: Padrão Editora, . Estrutura da língua portuguesa. Petrópolis: Vozes, 1982

[1] Prosódia trata dos estudos sobre variação na altura, intensidade, tom, duração e ritmo na fala. Sobre prosódia ver Cagliari (1989).

[2]

A ocorrência de velar seguida de glide será discutida na seção 4 do presente artigo. 